\title{
CULTURA PAULISTA NA TERAPIA COMUNITÁRIA INTEGRATIVA
}

\author{
PAULISTA CULTURE IN THE INTEGRATED COMMUNITY THERAPY
}

\author{
Josefa Emília Lopes RUIZ ${ }^{1}$ \\ Leandro Osni ZANIOLO ${ }^{2}$ \\ Luci Regina MUZZETI ${ }^{3}$ \\ Morgana Múrcia ORTEGA ${ }^{4}$ \\ Taísa Borges de SOUZA ${ }^{5}$
}

RESUMO: Este trabalho propõe resgatar os elementos típicos da cultura do estado de São Paulo e sua influência na constituição dos indivíduos enquanto valores, crenças e práticas que devem ser trabalhados no módulo de Antropologia Cultural do curso de Terapia Comunitária Integrativa, uma prática em saúde mental criada pelo Prof. Dr. Adalberto Barreto, que prioriza o acolhimento e a inclusão social. Consta o histórico do surgimento da TCI em vários polos formadores do estado e como o tema cultura vem sendo trabalhado nos cursos de formação. A ênfase na formação está no reconhecimento e respeito à diversidade e na valorização da cultura pelo indivíduo, funcionando como um agente de "empoderamento", melhorando sua autoestima e colaborando na transformação da realidade.

PALAVRAS CHAVE: Cultura paulista. Formação em terapia comunitária integrativa. Empoderamento.

ABSTRACT: This work aims to recover some typical elements of the culture of the State of São Paulo and its influence on the constitution of individuals as values, beliefs and practices that must be worked on in the Cultural Anthropology module of the Integrative Community Therapy course, a practice in mental health created by Prof. Dr. Adalberto Barreto, who prioritizes the reception and social inclusion. It presents the history of the emergence of TCI in various poles forming the state and how the theme culture has been worked on training courses. The emphasis on formation is that recognition, respect for diversity and appreciation of culture by the individual function as an agent of "empowerment," enhancing self-esteem and helping to transform the reality.

${ }^{1}$ Psicóloga - Terapeuta Comunitária e de Autoestima, formadora em TCI - Polo CENPE/FCLAR/UNESP/Araraquara. E-mail: jruiz@fclar.unesp.br

${ }^{2}$ Prof. Dr. do Departamento de Psicologia da Educação/Coordenador do Polo CENPE/FCLAR/UNESP/Araraquara. E-mail: zaniolo@ fclar.unesp.br

${ }^{3}$ Profa. Dra. do Departamento de Didática/Supervisora do CENPE /FCLAR/UNESP/Araraquara. Email: lucirm@fclar.unesp.br

${ }^{4}$ Fonoaudióloga - Terapeuta Comunitária e de Autoestima, formadora em TCI - Polo CENPE/FCLAR/UNESP/Araraquara. E-mail: mmo@fclarfclar.unesp.br

${ }^{5}$ Psicóloga - Terapeuta Comunitária e de Autoestima, formadora em TCI - Polo CENPE/FCLAR/UNESP/Araraquara. E-mail: taisa@ fclar.unesp.br 
KEYWORDS: Paulista culture. Education in integrative community therapy. Empowerment.

Para que possamos tecer reflexões com relação à cultura paulista na Terapia Comunitária Integrativa (TCI), considerando sua riqueza e pluralidade, há necessidade de contextualizá-la em seus aspectos geográficos, históricos, com particularidades regionais e seus reflexos na prática da TCI.

Segundo a Agência Paulista de Promoção de Investimentos e Competitividade (INVESTE SÃO PAULO, 2015) “O estado de São Paulo é um dos mais importantes focos de desenvolvimento do Hemisfério Sul”. Sua localização estratégica ultrapassa, em muito, seus limites territoriais, estendendo-se pelas demais Unidades da Federação e por diversos países da América do Sul. Segundo dados do Investe São Paulo (2015), o estado de São Paulo está localizado na Região Sudeste do Estado e faz divisa com Minas Gerais, Mato Grosso do Sul, Paraná e Rio de Janeiro. Representando 3\% do território brasileiro, ocupa uma superfície de 248,2 mil km². Seu litoral é banhado ao longo de 622 km pelo Oceano Atlântico. De acordo com dados de 2012, da Fundação Sistema Estadual de Análise de Dados, o estado de São Paulo possui quase 42 milhões de habitantes. É a mais populosa unidade da Federação e em uma das mais densamente povoadas. Possui aproximadamente 168 habitantes por $\mathrm{km}^{2}$, em oposição a uma média nacional de aproximadamente 22 habitantes por $\mathrm{km}^{2}$. O estado de São Paulo é dividido em 645 municípios, agrupados em 15 regiões administrativas. Sua dinâmica regional constituiu uma rede de cidades que compreende um conjunto de metrópoles, aglomerados e centros urbanos formados por 173 municípios e $74 \%$ da população estadual. Fazem parte desse estado quatro Regiões Metropolitanas: São Paulo (19,9 milhões de habitantes), Campinas (2,8 milhões de habitantes) e Baixada Santista (1,7 milhão de habitantes). Além disso, há uma aglomeração urbana que possui 718 mil habitantes e quatro unidades regionais com cerca de 3,4 milhões de habitantes. Com relação à hidrografia do estado, a maior parte dele está localizada na Bacia Hidrográfica do Rio Paraná, onde se destaca um de seus formadores, o Rio Grande, além de afluentes como o Tietê e o Paranapanema. Outros importantes rios do estado são o Turvo, o Pardo, o Rio do Peixe, o Paraíba do Sul, o Piracicaba e o Ribeira do Iguape. Além do Oceano Atlântico e dos rios Grande, Paranapanema e Paraná, seus principais limites 
naturais são a Serra da Mantiqueira e a Serra do Mar, a leste, e a Serra do Taquari, ao sul.

\section{Cultura x história do estado de São Paulo}

Cultura significa cultivar e tem sua origem no latim colere. De forma geral a cultura é todo aquele complexo que engloba o conhecimento, a arte, as crenças, a lei, a moral, os costumes e todos os hábitos e aptidões adquiridos pelo homem não somente em família, como também por fazer parte de uma sociedade como seu membro. Segundo Marconi e Presotto (2008 apud GOMES, 2013, p. 39):

Para a antropologia cultural, as pessoas são resultantes de suas crenças, costumes, mitos, valores, rituais, religião, língua e do que fazem a partir de sua história de vida. Há um referencial histórico e sociocultural na construção da identidade individual e coletiva. A partir da cultura se desenvolvem habilidades e competências para pensar, avaliar, discernir valores e fazer opções no cotidiano. Com base na identidade individual e coletiva, as pessoas podem se afirmar, se aceitar, assumir uma identidade como cidadãos, romper com relações de dominação e exclusão social pautadas em culturas que desvalorizam outras. A diversidade cultural é rica de fonte de saberes, sendo um recurso a ser reconhecido, valorizado e mobilizado na busca de resolução de problemas coerentes com as necessidades e realidades culturais das comunidades.

Segundo o criador da Terapia Comunitária Integrativa, Barreto (2008), uma cultura reflete a diversidade e a riqueza de seu povo, que para se desenvolver é levado constantemente a ultrapassar fronteiras, sejam de origem política, geográfica, econômica ou ideológica. Cada raça carrega em si suas peculiaridades, sua cultura, que envolve: língua, religião, mitos rituais, sua maneira de trabalhar, de ser e viver, ou seja, sua própria identidade. $\mathrm{O}$ autor coloca que:

Se os elementos culturais que fazem do índio um índio, do negro um negro, do branco um branco, do amarelo um amarelo, do pardo, pardo, do francês, francês [...] forem destruídos, acontecerá o mesmo que aconteceria, se destruíssemos a teia que sustenta a aranha. (BARRETO, 2008, p. 243-244)

Nesse sentido, destaca que a aranha precisa de sua teia para conseguir seu alimento e sobreviver, assim como o homem precisa do apoio e suporte de sua cultura para se reconhecer como indivíduo. 
Considerando a importância da cultura para seu povo, focaremos neste trabalho a cultura do estado de São Paulo e sua influência na realidade de vida das pessoas e, por extensão, nos trabalhos desenvolvidos na Terapia Comunitária Integrativa.

A maioria das expressões da cultura tradicional paulista tem suas raízes, basicamente, em três grandes influências: a portuguesa, a indígena e a italiana. Pode ser dividida em duas variações: a caipira, que é a do interior do estado, e a das cidades da Grande São Paulo: caiçara na maioria das cidades do litoral paulista. De fato, o estado de São Paulo influenciou ativamente o país na política e na economia, repercutindo também em influências culturais.

Sabemos que a cultura paulista é uma das mais ricas dos estados brasileiros, pois este é um estado que recebeu fortes ondas migratórias e imigratórias nos séculos XX e XXI, levando costumes distintos para um mesmo lugar e criando uma cultura singular, seja na música, na literatura ou nas artes plásticas. Algumas dessas manifestações não são exclusivas do estado, devido às expedições realizadas por bandeirantes paulistas, a partir do início do século XVI, na área que compreende os atuais estados de Goiás, Mato Grosso, Minas Gerais, e Mato Grosso do Sul, entre outros, e que influenciaram estes estados no aspecto cultural. Por isso, encontramos uma mistura de costumes nas heranças culturais, nas populações regionais e, por extensão, nas práticas da Terapia Comunitária Integrativa.

Destacaremos, a seguir, algumas das principais manifestações culturais presentes no estado de São Paulo:

A música popular paulista tradicional, assim como no resto do Brasil, foi influenciada principalmente pelas tradições da Europa e dos índios. Uma das marcas da cultura brasileira, refletida em sua música, é a alegria, presente fortemente nos ritmos de samba. (CULTURA DE SÃO PAULO, 2015). O samba surgiu da mistura de estilos musicais de origem africana e brasileira. É tocado com instrumentos de percussão (tambores, surdos, timbau) e acompanhado por violão e cavaquinho. Geralmente, as letras de sambas contam a vida e o cotidiano de quem mora nas cidades, com destaque para as populações pobres. O termo samba é de origem africana e tem seu significado ligado às danças típicas tribais do continente. Os grandes precursores do samba da atualidade foram: Noel Rosa, autor de Conversa de Botequim; Cartola, de As Rosas Não Falam; Dorival Caymmi, de O Que É Que a Baiana Tem?; Ary Barroso, de Aquarela do Brasil; e Adoniran Barbosa, de Trem das Onze. Na nova geração do samba - década de 1970 e 1980, destacam-se: Paulinho da Viola, Jorge Aragão, João 
Nogueira, Beth Carvalho, Elza Soares, Dona Ivone Lara, Clementina de Jesus, Chico Buarque, João Bosco e Aldir Blanc (SAMBA, 2015). Esse ritmo desenvolveu pontos de aglutinação de diversas festas religiosas tradicionais no estado, como a Festa do Bom Jesus, dos Santos Reis, de São Benedito, dentre outras.

Outro ritmo de música popular bastante predominante no país e de origem paulista é a moda de viola, tendo sido amplamente divulgada por Cornélio Pires, durante o século XX, e que atingiu seu ápice com cantores e compositores como Tonico e Tinoco, Tião Carreiro e Pardinho, Vieira e Vieirinha, Sérgio Reis e Renato Teixeira, que influenciam os compositores e cantores sertanejos na atualidade. (CULTURA, 2015).

Dentre as danças difundidas na cultura paulista, segundo dados da Cultura de São Paulo (2015), destacam-se a catira ou cateretê, o cururu, os fandangos, os congos. Vale ainda ressaltar as festividades como dos Santos Reis.

A Catira ou Cateretê é a dança de palmeados e sapateados, realizada por homens postados de frente. Atualmente, tem-se aberto espaço para a participação feminina nesta dança. Ocorre com o uso de duas violas ou viola e violão e utiliza-se de movimentos intercalados pela moda de viola, com cantorias recitativas. É uma dança comum em festas familiares e religiosas tais como o Divino, São Benedito e Santa Cruz. (CULTURA, 2015).

O Cururu é uma espécie de cantoria de desafio com acompanhamento de viola e/ou violão, acompanhada por uma dança de roda em sentido anti-horário. Além da cantoria de desafio, o cururu identifica um gênero (padrão rítmico) da música caipira, diferente da moda de viola, do catira e da toada. Este ritmo é comum em noitadas de Piracicaba, Capivari, Tietê, Sorocaba, Tatuí e outras localidades. (CULTURA, 2015).

Os Fandangos são danças de grupos, que usam o bater dos pés como referência. Geralmente é executado por homens, em duas alas, frente a frente. São acompanhadas de violas, sanfonas e pandeiros. Eram danças muito utilizadas para diversão dos tropeiros, em pousadas do interior paulista. Apresentam-se em duas principais modalidades: 1 - Fandango de tamancos: utilização de tamancos de madeira de laranjeira, com fendas nos calcanhares para ressoar o som do sapateado. Podemos ver exemplos dessa modalidade, dentro do estado de São Paulo, em Olímpia, em Ribeirão Grande, em Capão Bonito; 2 - Fandango de chilenas: utilização de esporas não dentadas, atadas à bota dos tropeiros paulistas - que servem de instrumento de percussão -, de origem espanhola. A dança lembra gestos e nomes que fazem referência 
ao cotidiano dos tropeiros. Existem vários grupos de fandango formados ao longo da rota do tropeirismo. Ocorre em Capela do Alto, Sorocaba e Tatuí. O festival de Folclore em Olímpia também é palco de diversas apresentações de grupos. (CULTURA, 2015).

Segundo Macedo (2015), os Congos ou Congadas são folguedos que geralmente aparecem na forma de cortejos, onde os participantes cantam e dançam, em festas religiosas ou profanas, homenageando, de forma especial, São Benedito. São utilizados instrumentos de percussão, com uso de muitas caixas, com peso, estimulando momentos de bailado e manobras complicadas. As roupas usadas são coloridas, as caixas são enfeitadas com fitas. Estas festas fazem parte do folclore brasileiro e reúnem elementos das tradições tribais de Angola e do Congo. Nesta representação cultural, entidades dos cultos africanos são identificadas aos santos do catolicismo (sincretismo religioso). Sob esta influência, canalizam promessas de devotos aos Santos homenageados. (CULTURA BRASILEIRA, 2015).

Ainda segundo este autor, os Congos aparecem em outros estados, mas no estado de São Paulo as mais completas são as congadas do Litoral Norte (Ilhabela e São Sebastião), por suas estruturas complexas e presença das marimbas. Também são comuns em cidades como Santo Antônio da Alegria, no interior do Estado.

Com relação às festividades, a devoção aos Santos Reis natalinos é grande em todo o estado, variando as denominações para as festas em sua homenagem: Ternos de Reis, Folias de Reis, Reiadas ou simplesmente Reis. Na Grande São Paulo, sob influência da industrialização, o ciclo começa em novembro, atuando os grupos só nos finais de semana para cumprir sua Jornada. Nas casas, continuam sendo armados presépios, alguns artísticos e com o mesmo brilho e importância de outrora; outros mais singelos, expressão da religiosidade popular. (MACEDO, 2015). Folias de Reis, ao lado de Ternos e Companhias, refere-se a grupos de pessoas que, por devoção aos santos, peregrinam de casa em casa de amigos e devotos, do dia de Natal até 06 de janeiro, cantando temas religiosos relacionados à Profecia, ao nascimento de Jesus Menino e à Visita dos Reis Magos. Tocam instrumentos e cumprem os rituais de chegada e despedida, atendendo a pedidos, tirando promessas, (ajudando os devotos a cumprir suas promessas). Os bastiões, marungos e palhaços são personagens presentes nesses folguedos, com mascaras confeccionadas nos mais diversos materiais (peles de animais, tecidos, napa, tela de arame, cabaças, papelão, colagem de papel). Usam trajes vistosos, dançam, declamam romances tradicionais, jogando versos decorados. É um folguedo bastante expressivo no estado. Ocorre em uma grande maioria de cidades do estado, tais 
como Altinópolis, Araraquara, Barretos, Batatais, Bebedouro, Brodósqui, Cajuru, Campinas, Cássia dos Coqueiros, Cidade de São Paulo, Cosmorama, Cunha, Dracena, Fernandópolis, Ribeirão Preto, Sales Oliveira, Santa Rosa do Viterbo, Santo André, São Bernardo do Campo, São Caetano do Sul, São Francisco, São Jose do Rio Preto, dentre outras. (MACEDO, 2015).

Vale ainda destacar as cantigas de rodas. As cantigas de roda, também conhecidas como cirandas, são brincadeiras que consistem na formação de uma roda, com a participação de várias crianças, que cantam, de mãos dadas, músicas de caráter folclórico, seguindo coreografias específicas. São muito executadas em escolas, parques e outros espaços frequentados por crianças. As músicas e coreografias são criadas por anônimos, que adaptam músicas e melodias. As letras das músicas são simples, fáceis de compreensão e trazem temas do universo infantil e da cultura local. Alguns exemplos bem conhecidos deste universo musical são: Capelinha de melão; Atirei o pau no gato, Escravos de Jô; Peixe vivo; Fui no Itororó; A canoa virou. Além de terem uma letra fácil de gravar, é permeada de rimas, repetições e trocadilhos, resultando a música numa brincadeira divertida. As cantigas e brincadeiras de rodas são comuns em todo o Brasil, e fazem parte de seu folclore. (CANTIGAS, 2015).

Segundo Araújo (2015) é pela utilização das músicas pelas crianças que a cantiga vai se tornando popular. As cantigas hoje conhecidas no Brasil têm origem europeia, mais especificamente em Portugal e Espanha. Esta origem, porém, não é notável, pois as letras e ritmos já se adaptaram tanto ao folclore brasileiro que são a expressão de nosso país. A autora ressalta que as cantigas de roda são muito importantes para a cultura de um determinado lugar. Elas contribuem para o conhecimento dos costumes, das crenças, dos valores, do cotidiano das pessoas, das festas típicas do local, das comidas, das brincadeiras, da flora, da fauna, dentre outras coisas. Contribuem também neste aspecto as histórias populares contadas oralmente, as cantigas de ninar e lendas, dentre outras.

Assim como as festividades e danças, a culinária paulista teve uma forte influência de diversas culturas. Podemos citar os portugueses, franceses, africanos, italianos, japoneses, alemães, entre outros. Dadas as peculiaridades geográficas, agrega fatores diferenciados entre a capital, o litoral e o interior. Influenciada pelo mar, a culinária praiana abusa de elementos da cultura portuguesa, tais como bolinhos, caldeiradas e ensopados. No interior, destaca-se a tradição caipira, reflexo dos costumes afro-indígenas misturados aos hábitos portugueses e à culinária 
dos tropeiros que, apesar de ter praticamente desaparecido, ainda sobrevive em pratos típicos como a mandioca frita, o arroz carreteiro e o feijão gordo. A cidade de Barretos, onde ocorre a famosa festa do Peão, difunde a culinária típica dos tropeiros, e Campos do Jordão é referência gastronômica no estado, onde ofondue é uma preferência. Algumas comidas típicas do estado: Afogado, Arroz de Pescador, Bala de Café, Bananinha, Bolinho Caipira, Bolinho de Camarão, Bolinho de Mandioca, Bolinho de Siri, Bolo Coruja, Bolo de Milho, Bolo de Roda, Camarão à grega, Curau, Cuscuz à paulista, Galinhada, Leitão a pururuca, Mandioca Frita, Paçoca de Amendoim, Paçoca de Carne Seca, Picadinho, Risoto Paulista de Camarões, Rosquinha de pinga, Sanduíche de Mortadela, Sequilho de Coco, Virado de Ervilha, Virado de Frango. (CULINÁRIA, 2015).

Além das representações culturais acima citadas, são também típicos da cultura paulista, em todo o estado, outras manifestações, tais como o artesanato, presente no trançado e nas cerâmicas; as cavalarias de cunho religioso ou lazer, que refletem o gosto pelo trato com os cavalos; e festas religiosas famosas, como as festas do divino, de São Benedito, Santo Antônio e de Nossa Senhora da Aparecida, marca da religiosidade forte em nossa cultura.

Figura 1: Mapa do Patrimônio Imaterial da Cultura do Estado de São Paulo

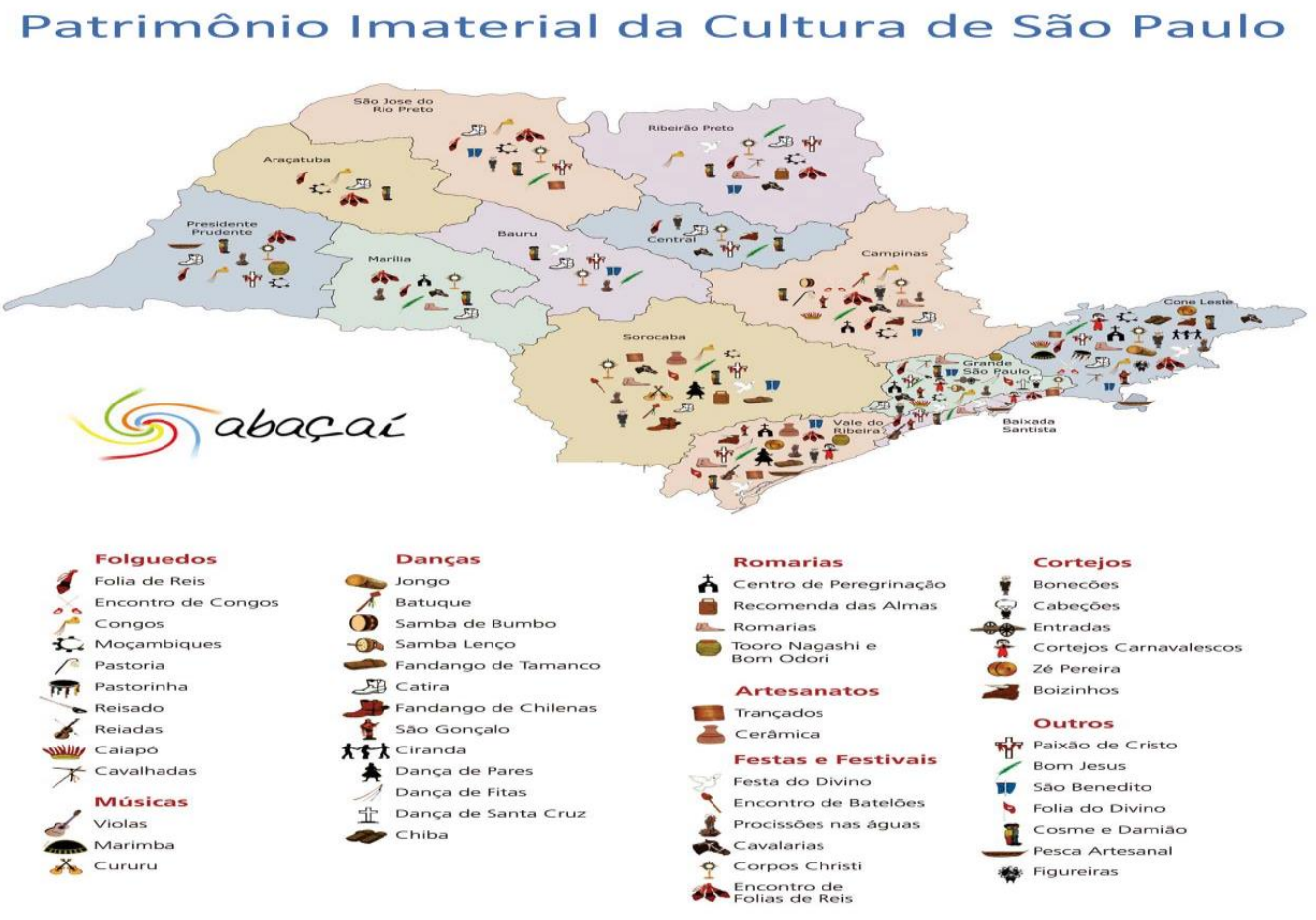

Fonte: Macedo (2015). 
Também fazem parte do legado cultural os ditados populares, que são expressões que com o passar dos anos se mantém imutáveis e ilustram exemplos morais, filosóficos e religiosos de uma cultura. Eles são passados de geração a geração e são consagrados pelo uso, embora nem sempre os autores sejam conhecidos. Fazem parte da cultura brasileira e representam os conhecimentos populares. Pesquisar a origem desses ditados é tarefa difícil para muitos historiadores (DITADOS, 2015). Não há quem nunca tenha ouvido ou falado, embora muitos guardem características regionais. Seguem alguns exemplos, que enriquecem nosso vocabulário cultural e ilustram essa forma de sabedoria:

\author{
"Antes tarde do que nunca; \\ A fruta proibida é a mais gostosa; \\ A sorte de uns é o azar de outros; \\ Água mole em pedra dura tanto bate até que fura; \\ A ocasião faz o ladrão; \\ Aqui se faz, aqui se paga; \\ Amigos, amigos, negócios à parte; \\ A união faz a força; \\ As aparências enganam; \\ A minha liberdade acaba onde começa a dos outros; \\ A cavalo dado não se escolhe os dentes; \\ A pensar morreu um burro; \\ Águas passadas não movem moinhos".
}

\title{
Terapia comunitária integrativa e práticas culturais
}

Toda a riqueza cultural de um povo, como as acima descritas, compõe sua identidade e ressoa em sua prática. Na Terapia Comunitária Integrativa não poderia ser diferente; a TCI, prática inovadora criada por Barreto na década de 80 se propõe a ser:

Um instrumento que nos permite construir redes sociais solidárias de promoção da vida e mobilizar os recursos e as competências dos indivíduos, das famílias e das comunidades. Procura-se suscitar a dimensão terapêutica do próprio grupo valorizando a herança cultural dos nossos antepassados indígenas, africanos, orientais e europeus, 
bem como o saber produzido pela experiência de vida de cada um. (BARRETO, 2008, p. 60).

O autor valoriza a diversidade cultural e considera que nas rodas de terapia comunitária é possível ao indivíduo se apropriar dos valores de sua história, de sua cultura, agregar novos valores, se "empoderar", sendo estes, elementos importantes na construção de sua identidade e cidadania. Seu modelo de atenção (primária) em saúde mental sai da patologização das doenças para focar o olhar no sofrimento humano, no indivíduo inserido em seu contexto. É um olhar sistêmico que vai em busca de competências, do resgate de sua autoestima e da autonomia de vida. Prioriza competências construídas ao longo da história de vida e favorece a formação de vínculos sociais solidários. Nesse sentido, Barreto (2008, p. 35) coloca que: "A comunidade deve funcionar como agente terapêutico no processo de inserção social, evitando a alienação da própria cultura, a perda da identidade, ajudando os indivíduos a se sentirem membros efetivos de sua comunidade".

Segundo o trabalho realizado por Gomes (2013), a Terapia Comunitária Integrativa nasceu para atender a demanda da população da favela de Pirambu, composta na época, em sua maioria, por indivíduos vivendo em situação de precariedade física, emocional e social. Exilados de sua terra de origem em função da seca, os sertanejos chegavam a capital cearense sem ter onde morar, sem ter trabalho, o que levou a formar em Fortaleza os grandes aglomerados periféricos chamados bolsões de miséria. Esses indivíduos viviam em situações vulneráveis de saúde, habitação, alimentação, educação, moradia, dentre outros, com escasso, quando não ausente, apoio governamental. Sua realidade era de dupla exclusão: de sua terra de origem e da nova terra escolhida. Viviam à margem da sociedade, empobrecidos de seus valores e crenças, sem perspectivas de futuro, sem informação quanto a direitos, redes de apoio, sem consciência de seu poder de cidadãos.

É essa a população que Barreto se depara quando vai propor atendimento considerando sua atuação como Doutor da Universidade Federal do Ceará, no final da década de 80 , com seus estagiários, onde percebe que só a prescrição de medicamentos seria falha, insuficiente e descontextualizada.

Aliado por sua história de vida e suas inquietudes de profissional comprometido com uma prática transformadora, Barreto se propôs a desenvolver um trabalho que pudesse integrar o saber formal e acadêmico ao saber popular, desenvolvendo um instrumento terapêutico acessível e adequado a essa população. Assim nasce a Terapia 
Comunitária Integrativa, que viria a ter, como um de seus pilares, a valorização e apropriação da identidade cultural de seu povo, sendo este um dos recursos de transformação pessoal e social.

Com este olhar, inseriu dentro da prática da TCI aquilo que é característico da cultura cearense, como as músicas, os ditados populares, os chistes e piadas, as comidas, as brincadeiras, dentre outros, recheadas de uma metodologia que agrega ao saber acadêmico a escuta, a fala, o acolhimento.

Desde que nasceu, a metodologia foi sendo sistematizada, sem perder a sua essência. Ganhou experiência e fundamentação, se legitimou como prática inovadora em saúde mental e resgate de cidadania, ultrapassou limites de estado e nação. Alcançou outras realidades e mostrou-se útil também em contextos empresariais, ONGs, instituições públicas e também com populações onde se destacam a pobreza de laços afetivos, mas não materiais, como por exemplo a população europeia.

Atualmente, a Terapia Comunitária Integrativa está presente na maioria dos estados da federação brasileira e luta para adquirir status de política pública na área da saúde. Em alguns estados, tais como o Piauí, foi regulamentada mediante resolução (006/2013/CMS-TE/2013) como prática de prevenção e promoção da saúde. No Rio Grande do Sul, foi criada a Resolução n. 695/13 - CIB/RS que aprova a Política Estadual de Práticas Integrativas e Complementares em Saúde, subsidiada por outras legislações que defendem a saúde integrativa e transdisciplinar (OMS 2002, PNPIC Brasil, 2006 ${ }^{\mathrm{a}}$, Portaria SES/RS n. 201/2012).

\section{Terapia comunitária integrativa $x$ cultura $x$ estado de São Paulo}

A primeira roda de Terapia Comunitária Integrativa realizada no estado de São Paulo ocorreu no bairro de Vargem Grande, zona sul da capital paulista, em agosto de 2000, mobilizada pela terapeuta comunitária Maria Selma do Nascimento ${ }^{6}$, após capacitação realizada em Belém do Pará.

Conforme relatos informais, em encontros de formadores, foi no ano de 2001 que outros profissionais e terapeutas paulistanos conheceram a técnica da Terapia Comunitária e seu criador, Adalberto de Paula Barreto. Esse grupo, sensibilizado com a

${ }^{6}$ Informações obtidas com Selma Maria Nascimento, por e-mail, em 03/03/2015. 
nova ferramenta de trabalho investiu na capacitação em Morro Branco/Ceará, trazendo posteriormente a formação para o Estado de São Paulo.

Com a capacitação desses profissionais, nasceram vários polos de formação, que foram institucionalizados a partir de 2004, com a criação da ABRATECOM Associação Brasileira de Terapia Comunitária, destacando-se entre os pioneiros na capital paulista, a partir de 2003: CEFOR, criado na Secretaria Municipal de Saúde/SP; NUFAC - Polo formador em Terapia Comunitária do Núcleo de Família e Comunidade da PUC-SP, atualmente o Polo Interfaci; CEAF - Centro de Estudos e Assistência à Família; TCendo.sp - Ensino e Desenvolvimento; ABCD Paulista e Uakti*Ara.

Desde então novos profissionais foram conhecendo o trabalho da Terapia Comunitária em suas rodas, em eventos, tais como: palestras, workshops, congressos e encontros de formadores. A partir daí foram investindo na capacitação, criando novos polos, na capital e no interior, somando hoje 15 polos formadores regulamentados, segundo o site da ABRATECOM (Associação Brasileira de Terapia Comunitária).

Mencionamos abaixo o cenário de alguns polos com relação ao contato com a Terapia Comunitária Integrativa e a incorporação dessa prática em sua realidade, assim como as influências da cultura paulista. Representam um recorte da realidade dos polos do estado de São Paulo, porém ilustram vivências, divulgam a história e mostram a importância de refletir a TCI com relação è cultura e poder pensar ações nesse sentido.

Para o CENPE - Polo formador em Terapia Comunitária Integrativa e Curso Cuidando do Cuidador desde 2004, o nascimento da TCI surgiu com a participação das profissionais deste Centro em um Workshop realizado em 2003, organizado pelas Professoras do Núcleo de Família e Comunidade do Programa de Estudos, PósGraduação em Psicologia Clínica da PUC/São Paulo, em especial Rosa Maria Macedo, Marilene Grandesso, Matilde Néder e Ceneide de Oliveira Cerveny. Sensibilizadas pela riqueza e simplicidade da técnica e seu alcance social para grandes grupos, as profissionais do CENPE/Faculdade de Ciências e Letras, viram nesse instrumento um recurso para trabalhar com o grande contingente de alunos que buscavam atendimento psicológico e social na Universidade. Visando à capacitação da equipe, o primeiro curso foi montado na Faculdade e sua participação estendida para o público em geral, formando na primeira turma mais de 70 terapeutas.

Como elementos da cultura local, o polo CENPE utiliza em sua prática brincadeiras, dinâmicas de grupo, músicas, cantigas de roda, danças circulares, ditados 
populares, regados, sempre que possível com guloseimas compartilhadas, tais como bolos de roda e sucos. Realiza na formação um trabalho de resgate da cultura familiar, solicitando aos alunos objetos, materiais, fotos, comidas e outros que possam representar a história da família, os antepassados e suas raízes, proporcionado uma reapropriação de sua história.

Para o MISC/São José do Rio Preto, coordenado por Lucimar Ianelo ${ }^{7}$, a TCI chegou em 2008, após sua participação no CDC - Conselho Deliberativo e Consultivo da Abratecom, realizado em Araraquara/SP. O desejo de levar a formação para São José do Rio Preto levou a coordenadora a transformar sua empresa num polo de formação em TCI, após articulações com terapeutas de polos mais experientes, como a Graça do Polo da Bahia, e após cumprir os protocolos oficiais exigidos na legislação da ABRATECOM, tendo, para tanto, suporte da terapeuta Mari Elaine Leonel Teixeira do CENPE/UNESP/Araraquara. Desta forma, em 2008 foi capacitada a primeira turma. Os elementos culturais mais utilizados por este Polo em sua formação e rodas são as músicas e danças. Uma comemoração típica e forte nesta região é a festa de folia dos Santos Reis, trabalhada no módulo relacionado à antropologia cultural. Os alunos trazem recursos como músicas, roupas e danças típicas dessa representação, que está presente na maioria das histórias. As guloseimas da região também aparecem como representação cultural dos alunos, culminando na revelação de talentos dos participantes e na troca de receitas. O churrasco, com a típica linguiça cuiabana, também é ingrediente incorporado nesta região, que não falta nas comemorações durante os módulos.

A chegada da TCI para o polo UNIFESP/Enfermagem - Nós te apoiamos, na cidade de São Paulo, coordenado pela Profa. Ana Lúcia de Moares Horta ${ }^{8}$ ocorreu inicialmente mediante curso oferecido pela Profa. Dra. Marilene Grandesso, do Núcleo de Família e Comunidade da PUC/São Paulo. Após o contato inicial, a coordenadora participou da primeira turma de formação, ministrada pelo Prof. Dr. Adalberto Barreto e organizada pelo NUFAC/PUC/SP em 2003. Dando sequência à formação, as rodas de Terapia Comunitária Integrativa tiveram início na UNIFESP, com a participação de estudantes, funcionários e população em geral. As atividades de formação envolveram depois um trabalho em parceria com a Fundação Zerbini, para 5 Unidades Básicas de Saúde, por 2 anos e meio, formando a primeira turma em 2004.

${ }^{7}$ Informações obtidas com Lucimar Ianelo por email em 28/02/2015.

${ }^{8}$ Informações obtidas com Ana Horta por e-mail em 27/02/2015. 
Neste polo em São Paulo, a cultura paulista sempre está presente, desde a formação até as rodas. São utilizadas cantigas, lendas e histórias do local, enriquecidas pelo aculturamento de pessoas migrantes de outros estados.

A equipe de Formadores do polo Piracema, coordenado por José Orivaldo Simonetti ${ }^{9}$, fez o Primeiro Módulo do curso de formação em TCI em abril de 2003, em São Paulo, com o Prof. Dr. Adalberto Barreto. Esse encontro foi organizado pelo CEAF - Centro de Estudos e Assistência à Família e o Instituto Sistemas Humanos. Esse primeiro contato com a TCI foi um grande incentivador para que o grupo de profissionais envolvidos dessa continuidade a um processo de construção de uma associação sem fins lucrativos, que veio a ser fundada com o nome de Grupo Piracema, em fevereiro de 2005. O Grupo Piracema foi fundado por terapeutas sistêmicos de família, com o objetivo central de desenvolver trabalhos que colaborassem para o fortalecimento individual e coletivo de comunidades vulneráveis. Em 2008, parte dos fundadores do Grupo Piracema completou seu curso de formação em TCI, com o Prof. Dr Adalberto Barreto, em Morro Branco. A seguir, em 2009, esse grupo fez o Curso de Formação para Intervisores em TCI em São Paulo/SP, também com o criador da técnica, juntamente com a Profa. Ms. Miriam Rivalta Barreto e a Prof. Dra Marilene Grandesso. Em 2010, o Grupo Piracema foi certificado como polo formador em TCI.

Dentre os recursos da cultura paulista mais utilizados nas práticas da TCI naquele polo, destacam-se as brincadeiras musicais, comuns no estado de São Paulo, nas escolas, nos acampamentos de Organizações que desenvolvem atividades com crianças e adolescentes, como ACM, Grupos de Escoteiros, e outras. São brincadeiras que proporcionam aquecimento e interação entre os participantes das rodas ou cursos. Como exemplos, citamos: "Escravos de Jó", "Boneca de Lata", "July Baby" e "Baile dos Movimentos".

Segundo informações apresentadas pela terapeuta comunitária Liliana Beccaro Marchetti $^{10}$ do TCendo.sp - ensino \& desenvolvimento, a primeira roda de terapia comunitária que fizeram foi em 11/08/2001, numa comunidade religiosa no bairro do Rio Pequeno, na capital de São Paulo, uma semana após chegarem da capacitação feita no Ceará com o Prof. Dr. Adalberto Barreto e certificados pela Universidade Federal do Ceará. Este grupo ocorreu mobilizado pela assistente social Maria da Salete Vianna. Após a volta da capacitação em Morro Branco, em julho de 2001, a mando do professor

${ }^{10}$ Informações obtidas com Liliana Beccaro Marchetti, por e-mail, em 22/04/2015. 
Adalberto, foram realizadas 10 rodas de terapia comunitária; após isso, este grupo retornou em fevereiro de 2002, para mais uma semana de capacitação em Morro Branco. Então, numa parceria do TCendo.sp - ensino \& desenvolvimento com o Interfaci/NUFAC, em Janeiro de 200,3 no Hotel Terras Altas, em Itapecerica da Serra, foi organizada a primeira capacitação em São Paulo ministrada pelo Prof. Dr. Adalberto Barreto. Nesta ocasião germinou a primeira possibilidade de capacitação visando uma política pública em São Paulo, onde este polo teve o privilégio de participar, fazendo a intervisão de parte dos 350 profissionais capacitados pela prefeitura de São Paulo em 2003 e 2004. Então o TCendo.sp - ensino e desenvolvimento, configurou-se como polo a partir de março de 2003. Foi fundado pela psicóloga Liliana Beccaro Marchetti e pela socióloga Lia Fukui.

Em relação aos elementos da cultura paulista utilizados na TCI, este polo destaca a grande diversidade cultural existente na capital, que se influenciam mutuamente. Então, nas rodas de terapia comunitária integrativa no PROJEPSI do Instituto de Psiquiatria do HCFMUSP, por exemplo, estão presentes: índio, italiano, cearense, baiano, japonês, goiano, carioca, paraense, boliviano, paranaense, peruano, enfim, uma multiplicidade de culturas. O que este polo verifica em suas rodas é uma grande disponibilidade de todos para conhecer a cultura de todos, desde que traga benefícios ao grupo. A cada música, brincadeira interativa de aquecimento e compartilhamento descobre-se que cada um dá o seu melhor, dentro da cultura que conhece, trazendo algo para o grupo: música, comida, pensamento, visão de mundo, no clima respeitoso e acolhedor da roda. Desta forma, cada grupo tem uma expressão cultural específica, cuja diferença é aproveitada para criar uma rede solidária. As pessoas compartilham no grupo, suas músicas orações, oferecendo o que lhes dá conforto e saber viver.

O mesmo ocorre nas capacitações deste polo, onde é estimulada a busca da cultura de cada aluno. Além disso, trabalha-se para que eles honrem suas culturas e também para que a capacitação seja um catalizador da multiplicidade cultural que encontrarão em suas futuras rodas. Foi realizado um levantamento em uma das capacitações deste polo onde os alunos descobriram seus antepassados: brasileiros, italianos, japoneses, portugueses, negros, índios, mineiros, baianos, africanos ou portugueses/italianos/árabes, índios/portugueses/negros/franceses/ingleses, 
espanhóis/negros/índios, italiano/portugueses/alemães, índios/negros/portugueses. Portanto, segundo a coordenadora, encontra-se nas rodas a mesma multiculturalidade.

Nas rodas e/ou capacitações, os alunos são convocados a cantar, contar piadas, estórias e poesias, que tenham a ver com o tema que estão trabalhando durante a roda ou num pilar teórico, e são convidados a conhecer a diversidade cultural do grupo e consequentemente da megalópole.

\section{Considerações finais}

Percebemos que cada polo, em sua formação e na condução de suas rodas de terapia comunitária integrativa, vai inserindo os elementos típicos de sua região e se apropriando de outros, considerando suas características, a população atendida e as trocas realizadas com essa comunidade.

Considerando a formação em Terapia Comunitária Integrativa, nós, do polo CENPE, destacamos a importância da cultura ser trabalhada ao longo de todos os módulos, embora sua ênfase apareça didaticamente no Módulo da Antropologia Cultural, sendo este um dos pilares teóricos desta teoria. Nesse módulo, os elementos da cultura são trabalhados por meio de dinâmicas e atividades diferenciadas, onde o foco é o resgate e a valorização das heranças culturais familiares. Este é um momento de muita sensibilidade e afetividade entre os participantes, em que, por meio das pesquisas das histórias transgeracionais e da partilha com o grupo são resgatados os valores, as tradições e crenças, em sua diversidade e pluralidade, que compõem a identidade de cada um.

Com a partilha, o grupo reconhece a riqueza de suas histórias e tem a possibilidade de se "empoderar", se apropriando de suas competências.

No CENPE, onde há 10 anos estamos desenvolvendo trabalhos advindos da TCI e do Cuidando do Cuidador, como o Programa Qualidade de Vida e o Programa de Acolhimento aos Alunos da Universidade - Espaço de Conversas e Terapia Comunitária Integrativa, fica claro e forte a importância de ser valorizada a cultura desses grupos. Percebemos pelas rodas e pelas partilhas nesses trabalhos que o empoderamento, o fortalecimento de si e do grupo, só é possível se nos apropriarmos daquilo que somos, daquilo que aprendemos, da valorização da cultura dos nossos antepassados e do local em que vivemos. Aprendemos com o Prof ${ }^{\circ}$ Dr. Adalberto 
Barreto que quando nos distanciamos de nossas histórias, de nossa identidade, produzimos a autoexclusão e ficamos colados no papel de vítimas. Dessa forma, a precariedade psíquica se apresenta, perdemos nossos valores, perdemos a noção do EU, do TU e do NÓS.

Resgatar nossas pérolas é uma reflexão que passa pelo resgate de nossos valores e de nossa cultura. O empoderamento é um processo dinâmico, assim como a formação em Terapia Comunitária Integrativa. Trabalhar e valorizar o resgate da cultura do indivíduo ao longo de todos os módulos de formação em TCI deve ser uma prática constante, pois possibilita a este terapeuta uma formação dialética, que envolve: construção, desconstrução por incorporação e uma nova construção da realidade, síntese do processo dialético.

Outra reflexão que tecemos nessa prática é que embora nossa cultura seja muito rica e diversa, parece que ainda nos apropriamos de forma tímida desses recursos nas práticas de TCI. Muitas vezes é difícil lembrar de músicas, poemas, soltar o corpo para mexer, dançar, respirar. Questionamos se isso não se deve à cultura do estado ser fortemente direcionada para o trabalho, a produção, as tecnologias, o capital. O estado é considerado um dos maiores centros econômicos do país. As pessoas priorizam o trabalho em detrimento do lazer, do relaxar, não valorizam espaços para que a criatividade possa se manifestar, e isso acaba se refletindo em ações muitas vezes mecanizadas.

Um dos desafios que se apresentam para os formadores é construir e incluir na formação mais atividades de autoconhecimento que resgatem cada vez mais os elementos da cultura constituintes dos indivíduos, de sua essência, propulsores de valorização da autoestima e do empoderamento.

Nas teias da Terapia Comunitária Integrativa, a Cultura, uma vez sentida, compreendida e incorporada como valor, como força de transformação pessoal e social, maior a possibilidade de seus recursos serem utilizados de forma efetiva $\mathrm{e}$ transformadora pelo terapeuta comunitário e pelas pessoas que vivenciam as rodas de Terapia Comunitária Integrativa.

Que a Cultura do outro e a nossa se misturem ao longo do processo de aprendizagem do que é ser terapeuta comunitário e do que é conduzir rodas de terapia comunitária integrativa. 


\section{REFERÊNCIAS}

AGÊNCIA PAULISTA DE PROMOÇÃO DE INVESTIMENTOS E COMPETITIVIDADE [Investe São Paulo]. Localização estratégica. Disponível em: <http://www.investe.sp.gov.br/por-que-sao-paulo/localizacao-estrategica/>. Acesso em 26 jan. 2015.

ARAÚJO, A. P. Cantigas de Roda. Info Escola: Navegando e Aprendendo. Disponível em: <http://www.infoescola.com/folclore/cantigas-de-roda/>. Acesso em 30 jan. 2015.

BARRETO, A. Terapia Comunitária passo a passo. 3. ed. Fortaleza: Gráfica LCR, 2008.

CAMINHOS do campo ensina uma deliciosa receita de bolo de laranja. Rede Globo RPC. Disponível em: <http://redeglobo.globo.com/rpc/noticia/2015/02/caminhos-docampo-ensina-uma-deliciosa-receita-de-bolo-de-laranja.html $>$. Acesso em 02 mar. 2015.

CANTIGAS de roda: cirandas. Sua Pesquisa.com. Disponível em: <http://www.suapesquisa.com/folclorebrasileiro/cantigas_de_roda.htm>. Acesso em 30 jan. 2015.

COMIDAS típicas: São Paulo. Decolar.com: blog de viagens e turismo. Disponível em: <http://www.decolar.com/blog/dicas-de-viagem/comidas-tipicas-sao-paulo>. Acesso em 02 mar. 2015.

CULINÁRIA. Wikipédia livre. Disponível em:

<http://pt.wikipedia.org/wiki/Cultura_de_S\%C3\%A3o_Paulo>. Acesso em 26 jan 2015.

CULTURA brasileira: congada - festa folclórica une tradições africanas e ibéricas.

Pedagogia \& Comunicação, p. 3, ago. 2006. Disponível em: $<$ http://educacao.uol.com.br/disciplinas/cultura-brasileira/congada-festa-folcloricaune-tradicoes-africanas-e-ibericas.htm>. Acesso em: 30 jan. 2015.

CULTURA de São Paulo. Wikipédia livre. Disponível em: <http://pt.wikipedia.org/wiki/Cultura_de_S\%C3\%A3o_Paulo>. Acesso em: 26 jan 2015 .

DITADOS populares: de onde surgiram? Disponível em: <http://www.mulhervirtual.com.br/ditados.htm>. Acesso em: 06 fev. 2015.

DOMINGO começa o congado na capital do folclore nacional. Cidade de Asas. Disponível em: <http://cidadedeasas.blogspot.com.br/2013/08/domingo-comeca-ocongado-na-capital-do.html>. Acesso em: 30 jan. 2015.

GOMES, D. O. A expansão da terapia comunitária integrativa no Brasil e sua inserção em ações de políticas públicas nacionais. 154 f. Dissertação (Mestrado em Saúde da Família) - Universidade Federal do Ceará, Sobral, 2013. 
MACEDO, T. Manifestações da cultura tradicional do Estado de São Paulo. Abaçaí, Cultura e Arte. Disponível em: <http://revelandosaopaulo.org.br/rv/manifestacoes-dacultura-tradicional-do-estado-de-sao-paulo/>. Acesso em: 30 jan. 2015.

SAMBA e história do samba. Suapesquisa.com. Disponível em: <http://www.suapesquisa.com/samba/>. Acesso em: 27 jan 2015.

SIGNIFICADO de cultura. Significados.com.br. Disponível em: http://www.significados.com.br/cultura/. Acesso em: 29 jan. 2015.

TERESINA. Conselho Municipal de Saúde. Resolução n. 006/2013. Diário Oficial, Teresina, 16 abr. 2013. Disponível em:

<http://www.jusbrasil.com.br/diarios/86558513/dom-the-normal-15-05-2013-pg-7>.

Acesso em: 11 mar. 2015.

RIO GRANDE DO SUL (Estado). Secretaria da Saúde. Resolução n. 695/2013: anexo. Diário Oficial, Porto Alegre, 20 dez. 2013. Disponível em: <http://www.saude.rs.gov.br/upload/1388163773_cibr695_13.pdf>. Acesso em: 11 mar. 2015.

\section{Como referenciar este artigo}

RUIZ, Josefa Emília Lopes et al. Cultura paulista na terapia comunitária integrativa. Revista Temas em Educação e Saúde, Araraquara, v.12, n.2, p. 198-216, jul./dez. 2016. ISSN: 1517-7947.

Submetido em: 30/10/2016

Aprovado em: 20/11/2016 